http://jmscr.igmpublication.org/home/ ISSN (e)-2347-176x ISSN (p) 2455-0450 crossref DOI: https://dx.doi.org/10.18535/jmscr/v10i1.07

\title{
The effects of drug treatment and ADL instructions in patients with PLID among the adult populations at Dhaka Medical College Hospital
}

\section{Dr Ripon Kumer Saha ${ }^{* 1}$, Dr Moinuddin Hossain Khan², Dr Dilir Zamal',} Dr Aparajeya Bivab Bikash Baral ${ }^{4}$, Dr S.M Mazharul Islam ${ }^{5}$, Dr Md. Aminul Alam6, Professor D. Jahidul Islam ${ }^{7}$

${ }^{1}$ Assistant Professor, Department of Physical Medicine and Rehabilitation, Dhaka Medical College, Dhaka, Bangladesh

${ }^{2}$ Associate Professor, Department of Physical Medicine and Rehabilitation, National Institute of Traumatology and Orthopedic rehabilitation, Dhaka, Bangladesh

${ }^{3}$ Assistant Professor, Department of Physical Medicine and Rehabilitation, National Institute of Ear, Nose and Throat (ENT), Dhaka, Bangladesh

${ }^{4}$ Assistant Professor, Department of Physical Medicine and Rehabilitation, Dhaka Medical College, Dhaka, Bangladesh

${ }^{5}$ Assistant Professor, Department of Physical Medicine and Rehabilitation, Dhaka Medical College Dhaka, Bangladesh

${ }^{6}$ Indoor Medical Officer, Physical Medicine and Rehabilitation Department, Dhaka Medical College Hospital, Dhaka, Bangladesh

${ }^{7}$ Professor (current charge) and Head, Department of Physical Medicine and Rehabilitation, Dhaka medical college

Dhaka Bangladesh

*Corresponding Author

Dr Ripon Kumer Saha

\begin{abstract}
Background: PLID is one of the most common medical problems and causes a significant amount of disability and incapacity in different countries. PLID has a persistent and recurrent nature, with major consequences for individuals and society.

Objective: see the effects of drug treatment and ADL instructions in patients with PLID

Method: Randomized Clinical Trial was carried out in the department of Physical Medicine \& Rehabilitation in Dhaka Medical College Hospital, Dhaka, Bangladesh. Patients presenting with PLID in the age group of 18 to 50 years of both sexes attending in the Department of Physical Medicine \& Rehabilitation at Dhaka Medical College Hospital, Dhaka were included as study population. A total number of 70 patients with PLID who fulfilled the selection criteria were taken as study population and among them 35 patients were selected who were treated with drugs and ADL instruction.

Results: Among the 70 patients, majority of the patients were in the age group of 41 to 50 years which was 14 (40.0\%) cases. Male was - predominant than female which was 21(60.0\%) cases. The mean score of Schober's test before treatment was 3.6 0.7.The mean score of Schober's test 2 weeks after treatment was $4.5 \pm 0.6$, after 4 weeks $4.7 \pm 0.7$ and after 6 weeks was $5.3 \pm 0.8$. The mean score of VAS before treatment was $8.9 \pm 0.9,2$ weeks after treatment was $6.4 \pm 1.1$ ). 4 weeks after was $4.3 \pm 1.1$. and 6 weeks after was $2.9 \pm 1.4$.

Conclusion: This study was done on very small, selected admitted patients in department of medicine, Dhaka Medical College Hospital. Though the improvement was positive still the effects of drugs treatment was not that much impressive that treatment with traction.

Keywords: Drug treatment, PLID, LBP.
\end{abstract}




\section{Introduction}

PLID is a complicated ailment that necessitates a multidisciplinary approach that takes into account both the physical and socioeconomic components of the condition. The majority of lumber disc prolepses are laterally situated and cause symptoms in one or two spinal roots. The prolapsed disc tissue may compress the caudal equine, which runs from the lower half of the second lumber vertebra to the anterior and posterior roots of the spinal neurons L2 to S5. (Spannare BJ, 1978). Low back pain, whether with or without sciatica, is a leading cause of morbidity worldwide. (Akbar and Mahar 2002). LBP is a tough term to define, however it refers to a symptom complex in which pain originates in the lumbar spine and is transferred to the leg or foot. (Shakoor et al., 2010). Sciatica is pain that radiates from the lower back down one or both legs. Exertion, coughing, sneezing, or straining can all aggravate it. A sliding disk, which puts pressure on one of the roots of the sciatic nerve, is one of the most common causes, although it can also be produced by a temporary local entrapment or straining of the nerve or its roots. (Peterson and Renstrom 2001). The lifetime incidence of sciatica is 50-70 percent, and the incidence of sciatica can be as high as $40 \%$. (Akbar and Mahar 2002). Clinically serious sciatica owing to disc prolapse, on the other hand, affects 4-6 percent of the population. (Shakoor et al., 2010). In more than $90 \%$ of instances, intervertibral disc degeneration caused by a combination of causes can result in herniation, particularly at the L4-L5 and L5-S1 levels. (Akbar and Mahar 2002). The majority of herniation remains in the L3-L4 and L2-L3 segments. (Peterson and Renstrom 2001). The existence of pain, radiculopathy, and other symptoms is dependent on the location and severity of the herniation. A thorough medical history, physical examination, and neuroimaging can help distinguish herniated lumbar disc prolapse from other causes of low back pain and sciatica (Akbar and Mahar 2002). Pain is the most common sign of a prolapsed lumbar intervertebral disc, which can be felt in the lower back, the leg, or both. Sciatic discomfort (and anterior crural pain in upper disc disorders) is now widely acknowledged to be caused by direct impingement of a prolapse on a nerve root, rather than 'referred' discomfort from disordered joints or subluxated vertebrae (Logue 1953). Due to the variability of the patient population and the lack of a clear and useful approach, chronic low back pain is poorly understood and inadequately treated. It also results in job losses, which have increased more rapidly in recent years than any other frequent kind of disability (Ahmed et al., 2009). Pain in the lumbar area, groin, or anterior thighs is common in diseases affecting the upper lumbar spine. Lower lumbar spine diseases commonly cause pain in the buttocks, posterior thighs, and, in rare cases, the calves and foot. Radicular back pain is a type of intense pain that radiates from the lumbar spine to the leg and is caused by a nerve root. The radiating discomfort might be triggered by coughing, sneezing, or deliberate abdominal muscular contractions while lifting heavy objects or straining at a stool. In postures that stretch the nerves and nerve roots, the pain may worsen. Because the sciatic nerve (L5 and S1 roots) travels posterior to the hip, sitting strains it (Engtrom 2008). Overt mechanical compression of a nerve root or a chemically mediated inflammatory process can cause radicular symptoms. A disk protrusion is by far the most frequent compressing lesion (Barr and Harrast 2007). There are two sorts of mechanical benign causes: static (postural) and kinetic (faulty biomechanics). Increased lordosis, which involves excessive facet weight-bearing and foraminal closure, is the most common static reason. Alternatively, prolonged flexed postures on a daily basis may promote posterior nucleus migration, resulting in low back pain and possibly sciatic radiculopathy. The diagnosis is made based on the patient's medical history and a physical examination during which the pain is replicated. X-rays may reveal disk degeneration and facet arthritis, but clinical evidence is used to make the diagnosis. The focus 
of the treatment is on the source of the discomfort. Flexion or extension is given based on this principle. To improve posture and shift standing and working positions, body mechanics are still essential (Cailliet 1990). Back pain is fairly common in Western industrialized countries. In their active lives, over $80 \%$ of people will experience one or more episodes of back discomfort (Vander-Heijden et al., 1995). Bangladesh is an impoverished country with a large population, few resources, and ineffective management. As a result, a large proportion of disabled individuals presenting with low back pain cannot be managed with the current resources and management system for a variety of reasons. The prevalence of LBP varies by country, however it is consistently high in industrialized countries (Moyeenuzzaman 1992).

\section{Objective}

To observe the effect of drug treatment and ADL instructions in patients with PLID.

\section{Methodology}

This study was designed as a randomized control trial (RCT). This study was carried out in the Department of Physical Medicine \& Rehabilitation at Dhaka Medical College Hospital, Dhaka. This study was conducted from November 2013 to April 2014 for a period of six (6) months. All the patients who were presented with PLID in an age group of 18 to 50 years of both sexes attending in the Department of Physical Medicine \& Rehabilitation at Dhaka Medical College Hospital, Dhaka were included as study population. A total number of 70 patients presented with PLID who were fulfilled the selection criteria were taken as study population. Patients were selected by randomized sampling method. Incorporation of the patients in the two groups was performed by lottery. The sample size was calculated by the following formula (Steves K. Thompson). The sample size had been determined to measure a given proportion with a given degree of accuracy at a given level of statistical significance.

To determine the sample size, the formula is used;

$$
n=\frac{z^{2} p q}{d^{2}}
$$

Where,

$\mathrm{n}=$ the desired sample size which would help to measure the different indicators

$\mathrm{z}=$ the standard normal deviate, usually set at 1.96 at $5 \%$ level which corresponds to $95 \%$ confidence level.

$\mathrm{p}=0.0774$ (The prevalence rate of PLID is $7.74 \% 17)$

$\mathrm{q}=1-\mathrm{p}=1-0.0774=0.9226$

$\mathrm{d}=$ is the degree of accuracy level considered as $9.0 \%$.

Putting the values in the above equation the sample size $n$ is estimated as $\mathrm{n}=34$ (Estimated sample size)

In this study, 35 patients fulfilling the inclusion and exclusion criteria were enrolled in each group.

\section{Selection Criteria of Subjects Inclusion criteria}

- PLID patient with the complaints of

- Low back pain radiating below the knee (one or both limbs), often worse in the leg than back

- Pins and needles in the distal dermatome

- Persistent ridiculer pain in the L4, L5 or S1 dermatome with or without mild neurological deficit

- Severe disabling leg pain of 6-12 weeks duration

- Positive straight leg raising test

- Presence of intradiscal-nuclear hearniation (bulge) and protrusion in MRI.

- Aged 18-50 years of age

- Both male and female

- Patients who gave the consent to participate in the clinical trial

\section{Exclusion criteria}

- Patients with Cauda equina syndrome or severe paresis 
- Any history of trauma or fracture or spinal surgery

- Spondylo-arthrpathy, infection of spine, like $\mathrm{TB}$, osteomyelitis, pyogenic infection.

- Spinal tumour or secondary metastases

- Multiple myeloma, spinal osteoporosis

- Long term oral steroid intake

- Pregnancy

- History of major psychiatric illness;

- Patients not agreed to the assigned programme of treatment

- Presence of extrusion and sequestration in MRI.

\section{Data Collection and Analysis}

All data were compiled and edited meticulously. The data were screened and were checked for any missing values and discrepancy. All omissions and inconsistencies were corrected and were removed methodically. Computer based statistical analysis were carried out with appropriate techniques and systems. All data were recorded systematically in preformed data collection form (questionnaire) and quantitative data were expressed as mean and standard deviation and qualitative data were expressed as frequency distribution and percentage. Data was presented on a categorical scale compared between the groups using Chi-square (X2) or Fisher's Exact Probability test, while the data presented on a quantitative scale was compared between the groups using Student's 't' test. For all analytical tests, a probability $(\mathrm{p})$ value of $<0.05(\mathrm{p}<0.05)$ was considered statistically significant and $\mathrm{p}<0.01$ was considered highly significant but $p>0.05$ was taken as non-significant. Statistical analysis was performed by using window based computer software devised with Statistical Packages for Social Sciences (SPSS-17) (SPSS Inc, Chicago, IL, USA). 95\% confidence limit was taken. The summarized data was interpreted accordingly and was then presented in the form of tables.

\section{Results}

A total number of 35 patients were recruited for this study who were treated with pelvic traction considered for the study population

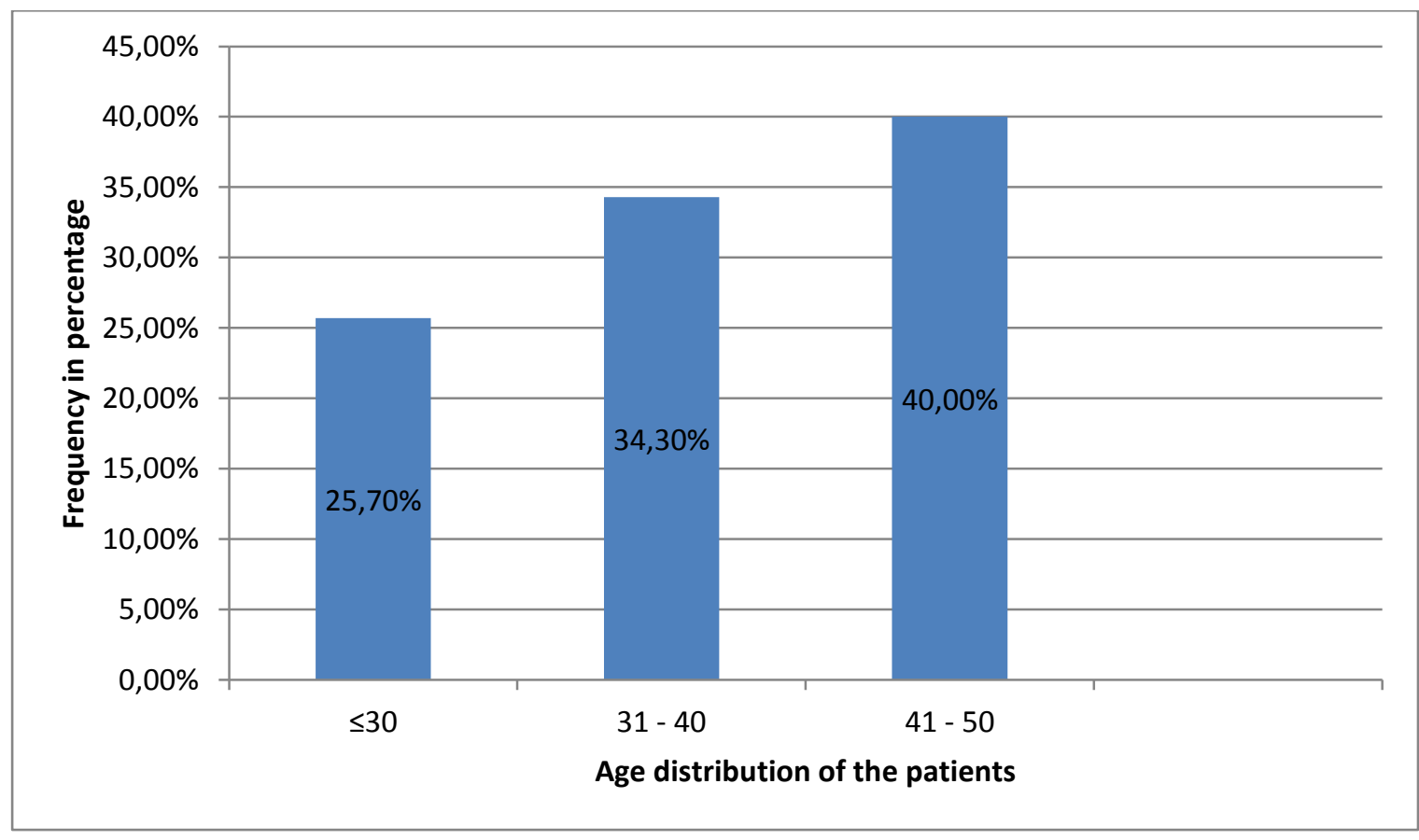

Figure 1: Age distribution of the patients

In figure 1 shows the age distribution of the patients. Majority of the patients were in the age group of 41 to 50 years which was $14(40.0 \%)$ cases followed by 31 to 40 years' group and less than or equal to 30 years' age group which were $12(34.3 \%)$ cases and $9(25.7 \%)$ cases respectively. The mean \pm SD age of the respondents was $37.3 \pm 8$. 


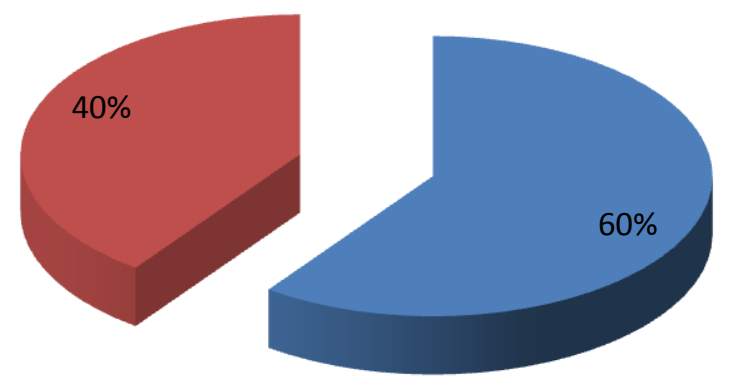

Male

Female

Figure 2: Gender distribution of the patients

In figure-2 shows the distribution of patients according to gender. Male was also predominant than female which was $21(60.0 \%)$ cases and $14(40.0 \%)$ cases respectively.

Table 1: Distribution of Study Population according to Occupation

\begin{tabular}{|l|c|}
\hline Occupation & n (\%) \\
\hline House wife & $6(17.1)$ \\
\hline Farmer & $4(11.4)$ \\
\hline Services & $12(34.3)$ \\
\hline Business man & $5(14.3)$ \\
\hline Student & $5(14.3)$ \\
\hline Hawkers & $1(2.9)$ \\
\hline Driver & $2(5.7)$ \\
\hline Total & $\mathbf{3 5 ( 1 0 0 . 0 )}$ \\
\hline
\end{tabular}

Chi-square test was done to measure the level of significance

Table 1 shows distribution of patients according to occupation. Most of the patients were services which was $12(34.3 \%)$ cases followed by housewife, businessman, student and farmer which was $6(17.1 \%)$ cases, $5(14.3 \%)$ cases, $5(14.3 \%)$ cases and $4(11.4 \%)$ cases respectively.
Table 2: Distribution of the patients according to complain

\begin{tabular}{|l|c|}
\hline Complain & (Mean \pm SD) \\
\hline $\begin{array}{l}\text { Duration of pain in days } \\
\text { Mean } \pm \text { SD) }\end{array}$ & $37.0 \pm 16.0$ \\
\hline Radiation of pain & $0(.0)$ \\
\hline Knee [n (\%)] & $24(68.6)$ \\
\hline Leg [n (\%)] & $11(31.4)$ \\
\hline Toes [n (\%)] & $13(37.1)$ \\
\hline Character of pain & $22(62.9)$ \\
\hline Constant [n (\%)] & $32(91.4)$ \\
\hline Intermittent [n (\%)] & $3(8.6)$ \\
\hline Relieving factors & $1(2.9)$ \\
\hline Rest [n (\%)] & $10(28.6)$ \\
\hline Lying flat [n (\%)] & $24(68.6)$ \\
\hline Meverity & \\
\hline Moderate [n (\%)] & \\
\hline Severe [n (\%)] & \\
\hline
\end{tabular}

Chi-square test was done to measure the level of significance; figure with parenthesis indicates percentage

In table 2 shows distribution of patients according to complain. $37.0 \pm 16.0$ days. LBP with radiation to leg was in most of the cases in both groups which was $24(68.6 \%)$ cases. LBP was intermittent in most of the cases in both groups which was $22(62.9 \%)$ cases. Most of the patients got relieve while resting which was 32 (91.4\%). Pain was severe in $24(68.6 \%)$ cases of group; however, pain was Moderate in 10 (28.6\%) cases. 
Table-3: Distribution of the patients according to aggravating factor

\begin{tabular}{|l|c|}
\hline Aggravating factor & Frequency \\
\hline Prolonged working & $17(14.0 \%)$ \\
\hline Leaning forward & $25(20.7 \%)$ \\
\hline Coughing & $20(16.5 \%)$ \\
\hline Sneezing & $19(15.7 \%)$ \\
\hline Prolonged standing & $17(14.0 \%)$ \\
\hline Menstruation & $8(6.6 \%)$ \\
\hline Prolonged sitting & $15(12.4 \%)$ \\
\hline
\end{tabular}

Student t-test was done to measure the level of significance; $\mathrm{TC}=$ total count

In table-3 shows the aggravating factor of the patients. leaning forward (20.7\%), coughing $(16.5 \%)$, sneezing $(15.7 \%)$, prolonged working $(14.0 \%)$ and prolonged standing $(14.0 \%)$ were the main aggravating factors in the group.

Table-4 Distribution of the patients according to laboratory investigation

\begin{tabular}{|l|c|}
\hline Laboratory investigation & $($ Mean \pm SD) \\
\hline TC $\left(x 10^{3}\right.$ per $\left.\mathrm{mm}^{3}\right)$ & $7.6 \pm 1.2$ \\
\hline ESR mm in $1^{\text {st }} \mathrm{hr}$ & $14.9 \pm 4.0$ \\
\hline HB gm/dl & $11.9 \pm 1.4$ \\
\hline RBS $(\mathrm{mmol})$ & $5.5 \pm 0.7$ \\
\hline Serum creatinine $(\mathrm{mg} / \mathrm{dl})$ & $0.9 \pm 0.2$ \\
\hline
\end{tabular}

Student t-test was done to measure the level of significance; $\mathrm{TC}=$ total count

In table-4 shows laboratory investigation of the patients. The mean total count (x103 per mm3) was $77.6 \pm 1.2$. The mean ESR ( $\mathrm{mm}$ in $1 \mathrm{st} \mathrm{hr}$ ) was $14.9 \pm 4.0$ The $\mathrm{HB}(\mathrm{gm} / \mathrm{dl})$ was $11.9 \pm 1.4$. The RBS (mmol) was $5.5 \pm 0.7$. The Serum creatinine $(\mathrm{mg} / \mathrm{dl})$ was $0.9 \pm 0.2$.

Table-5: Outcome of the patients according to Schober's test

\begin{tabular}{|l|c|}
\hline Assessment by Schober's test & $($ Mean \pm SD) \\
\hline Pre treatment & $3.6 \pm 0.7$ \\
\hline 2 weeks after treatment & $4.5 \pm 0.6$ \\
\hline 4 weeks after treatment & $4.7 \pm 0.7$ \\
\hline 6 weeks after treatment & $5.3 \pm 0.8$ \\
\hline
\end{tabular}

Student t-test was done to measure the level of significance

In table-5 outcome of patient assessed by Schober's test. The mean score of Schober's test before treatment were $3.6 \pm 0.7$. The mean score of Schober's test 2 weeks after treatment $4.5 \pm 0.6$

. The mean score of Schober's test 4 weeks after treatment were $4.7 \pm 0.7$. The mean score of Schober's test 6 weeks after treatment were $5.3 \pm$ 0.8 .

Table-6: Outcome of the patients according to VAS

\begin{tabular}{|l|c|}
\hline $\begin{array}{l}\text { Assessment by Visual analogue } \\
\text { scale }\end{array}$ & (Mean \pm SD) \\
\hline Pre treatment & $8.9 \pm 0.9$ \\
\hline 2 weeks after treatment & $6.4 \pm 1.1$ \\
\hline 4 weeks after treatment & $4.3 \pm 1.1$ \\
\hline 6 weeks after treatment & $2.9 \pm 1.4$ \\
\hline
\end{tabular}

Student t-test was done to measure the level of significance

In table- 6 shows outcome of patient assessed by visual analogue scale (VAS). The mean score of VAS before treatment were $8.6 \pm 1.1$ and $8.9 \pm$ $0.9(\mathrm{p}=0.302)$. The mean score of VAS in 2 weeks after treatment were $5.8 \pm 1.1$ and $6.4 \pm 1.1$ $(\mathrm{p}=0.022)$. The mean score of VAS in 4 weeks after treatment were $3.3 \pm 0.9$ and $4.3 \pm 1.1$ $(\mathrm{p}=0.001)$. The mean score of VAS in 6 weeks after treatment were $1.4 \pm 1.5$ and $2.9 \pm 1.4$ $(\mathrm{p}=0.001)$.

\section{Discussion}

A total number of 35 PLID patients were recruited for this study who were treated with drugs.

The distribution of patients according to gender is recorded. Male was also predominant than female which was $21(60.0 \%)$ cases and $14(40.0 \%)$ cases respectively. It has been found that male is more commonly affected by PLID. This may be due to the heavy works done by them. Similar to the present result Akbar and Mahar (2002) have reported that male is predominant in PLID group. The distribution of patients according to age is recorded. Majority of the patients were in the age group of 41 to 50 years $(40.0 \%)$ which was 14 cases followed by 31 to 40 years group (34.3\%) and less than or equal to 30 years age group (25.7\%). The mean \pm SD age of the patients was $37.3 \pm 8.1$. Similar to the present result Akbar and Mahar (2002) have mentioned that PLID occurs in mid age or onwards. Borman et al (2003) have reported that most of the cases PLID occur after 
the age of 35 years which is very similar to the present study result.

The distribution of patients according to occupation is recorded, most of the patients were services $(34.3 \%)$ followed by housewife $(17.1 \%)$, businessman (14.3\%), student (14.3\%) and farmer $(11.4 \%)$; service holder are more in the group . the disc prolapse is directly related with the occupation. The excess work load causes the PLID. Similar to this present study Kelsey et al (1984) have reported that occupation is directly related with the PLID and also have added that the occupation which is related with weight lifting is more associated with PLID. Similarly, Seidler et al (2003) have published a report regarding the pattern of occupation and the occurrence of PLID which is consistent with the present study. The distribution of patients according to complain were recorded in this study. The mean $( \pm \mathrm{SD})$ duration of pain was $37.0 \pm 16.0$ days. From this result it is very clear that the study population were in equal and non-significant difference of duration of pain. Therefore, at the time of analysis this doesn't create any overestimation of the result.

LBP with radiation to leg was present in most of the cases $68.6 \%$. In PLID patients LBP frequently radiated to the leg. LBP was intermittent in most of the cases $62.9 \%$ cases. Most of the patients got relieve while resting which was $91.4 \%$ cases. Pain was severe in $68.6 \%$ cases; however, pain was Moderate in $28.6 \%$ cases. Similar to the present result, Schwarzer et al (1995) were performed a study and have found that low back pain is one the most common clinical features of PLID. Waddell et al (1980) have reported that PLID caused severe low back pain with radiation to the leg.

The aggravating factor of the patients is recorded B leaning forward (20.7\%), coughing (16.5\%), sneezing $(15.7 \%)$, prolonged working $(14.0 \%)$ and prolonged standing (14.0\%) were the main aggravating factors. There are several aggravating factors of PLID of which prolong working is the most common to all. Similar to the present study Mundt et al (1993) have reported that non- occupational lifting of objects or children weighing 25 or more pounds with knees straight and back bent are associated with increased risk of herniated lumbar disc. Helia-Vaara (1987) has reported that different activities are directly related with PLID.

The mean total count (x103 per mm3) was $7.6 \pm$ 1.2. The mean ESR ( $\mathrm{mm}$ in $1 \mathrm{st} \mathrm{hr}$ ) was $14.9 \pm 4.0$ in The HB $(\mathrm{gm} / \mathrm{dl})$ was $11.9 \pm 1$. The RBS (mmol) was $5.5 \pm 0.7 \mathrm{in}$. The serum creatinine $(\mathrm{mg} / \mathrm{dl})$ was $0.9 \pm 0.2$. The outcome of patient assessed by Schober's test was recorded. The mean score of Schober's test before treatment were $3.6 \pm 0.7$. The mean score of Schober's test 2 weeks after treatment were $4.5 \pm 0.6$. The mean score of Schober's test 4 weeks after treatment were $4.7 \pm 0.7$. The mean score of Schober's test 6 weeks after treatment were $5.3 \pm$ 0.8 . The improvement rate was not that much good in this group. Borman et al (2003) have been reported similar result and have mentioned that pelvic traction with some medication have decreased the pain of PLID. In another study Vander-Heijden et al (1995) have reported that the low back pain is relieved after pelvic traction which is consistent with the present study.

The outcome of patient assessed by visual analogue scale (VAS) was recorded. The mean score of VAS before treatment $8.9 \pm 0.9$. The mean score of VAS in 2 weeks after treatment were $6.4 \pm 1.1$. The mean score of VAS in 4 weeks after treatment $4.3 \pm 1.1$. The mean score

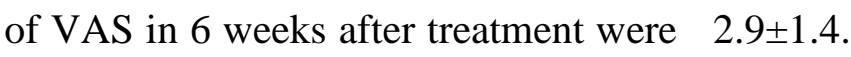
Akbar and Mahar (2002) have reported that the pain is relieved after treated with pelvic traction of the PLID patients which is similar to the present study result. Beurskens et al (1997) have reported that the efficacy of continuous traction for low back pain is very effective among the PLID patient which is consistent with the present study result.

\section{Conclusion}

This study was done on very small, selected admitted patients in the department of medicine, 
Dhaka Medical College Hospital. Though the improvement was positive still the effects of drugs treatment was not that much impressive that treatment with traction.

\section{References}

1. Ahmed MS, Shakoor MA, Khan AA; Evaluation of the effects of shortwave diathermy in patients with chronic low back pain, Bangladesh Med Res Counc Bull 2009; 35: 18-20.

2. Akbar A, Mahar A. Lumbar disc prolapse: management and outcome analysis of 96 surgically treated patients. J Pak Med Assoc. 2002;52(2):62-5.

3. Beurskens AJ, Henrica C, Regtop W, van der Heijden GJ, Lindeman E, Knipschild PG. Efficacy of Traction for Nonspecific Low Back Pain: 12• Week and 6• Month Results of a Randomized Clinical Trial. Spine 1997;22:2756-2762

4. Borman P, Keskin D. Bodur H. The efficacy of lumbar traction in the management of patients with low back pain. Rheumatol Int 2003; 23: 82-86

5. Cailliet R. Spine disorders and deformities. In: Kottke FJ, Lehmann FJ, eds. Krusen's Handbook of Physical Medicine and Rehabilitation. 4th ed.Philadelphia: W.B. Sunders; 1990: pp.792-809.

6. Hasan MA, Rahim MA, Siddiq MAB, Hossain MS, Taslim A, Paul S, Barua A, Hassn MMU, Islam MN, Haq SA. Study of spectrum of rheumatic diseases in the department of Physical Medicine and Rehabilitation, Chittagong Medical College Hospital, Bangladesh. Journal of Chittagong Medical College Teachers' Association, 2009; 20(1): 6-11.

7. Harte AA, Baxter GD, Gracey JH, The effectiveness of motorised lumbar traction in the management of LBP with lumbo sacral nerve root involvement: a feasibility study. BMC Musculoskeletal Disorders 2007
8. Helia-Vaara M. Body height, obesity, and risk of herniated lumbar intervertebral disc. Spine 1987;12:469-472

9. Logue VL. Treatment of lumbar disc prolapsed, Post Graduate Medical Journal 1953,234-42.

10. Moyeenuzzaman M. A study of patients with low back pain attending Physical Medicine Department of IPGM \& R [Dissertation]. BCPS, Dhaka. 1992

11. [Mundt DJ, Kelsey JL, Golden AL, Pastides H, Berg AT, Sklar J, Hosea T, Panjabi MM. An epidemiologic study of non-occupational lifting as a risk factor for herniated lumbar intervertebral disc. Spine 1993;18:595-602

12. Pellecchia G L; limbar traction : a review of the literature, JPSPT, November 1994,vol 20,No-5

13. Peterson L, Renstrom P. Sports injuries, their prevention and treatment, Martin Dunitz Ltd 2001,UK, 3rd ed,page-216-42

14. Pellecchia G L; limbar traction : a review of the literature, JPSPT, November 1994,vol 20,No-5

15. Schwarzer AC, Aprill CN, Derby R, Fortin J, Kine G, Bogduk N. The prevalence and clinical features of internal disc disruption in patients with chronic low back pain. Spine 1995;20:1878-1883

16. Saunders H D. Lumbar Traction, The Journal of Orthopaedic and Sports Physical therapy, Summer 1979, Vol. 1, No. 1, 36-45

17. Shakoor MA, Hassan SA, Moyeenuzzman M, Dev AK. Treatment with shortwave diathermy chronic low back pain. Journal of Chittagong Medical College Teachers' Association, 2010; 21(1): 40-4.

18. Spannare BJ. Prolapsed lumbar intervertebral disc with partial or total occlusion of the spinal canal. Acta Neurochirurgica. 1978;42(3-4):189-198

19. Vander-Heijden GJMG, Beurskens AJHM, Dirx MJM, Bouter LM, Lindeman E. 
Efficacy of Lumbar traction: a randomized clinical trial. Physiotherapy. 1995;81(1): 39-35

20. Waddell G, McCulloch JA, Kummel ED, Venner RM. Nonorganic physical signs in low-back pain. Spine 1980;5:117-125. 